\title{
PROGRESS ON THE DEVELOPMENT OF A HOLISTIC COUPLED MODEL OF DYNAMICS FOR OFFSHORE WIND FARMS: PHASE II - STUDY ON A DATA-DRIVEN BASED REDUCED-ORDER MODEL FOR A SINGLE WIND TURBINE
}

\author{
Z. Lin \\ Department of Naval \\ Architecture, Ocean and Marine \\ Engineering, University of \\ Strathclyde, Glasgow, UK \\ D. Cevasco \\ Department of Naval \\ Architecture, Ocean and Marine \\ Engineering, University of \\ Strathclyde, Glasgow, UK \\ O. Marjanovic \\ School of Electrical \& Electronic \\ Engineering, University of \\ Manchester, Manchester, UK
}

\author{
A. Stetco \\ School of Computer Science, \\ University of Manchester, \\ Manchester, UK
}

\author{
M. Collu \\ Department of Naval \\ Architecture, Ocean and Marine \\ Engineering, University of \\ Strathclyde, Glasgow, UK

\section{Barnes} \\ School of Electrical \& Electronic \\ Engineering, University of \\ Manchester, Manchester, UK
}

\author{
J. Carmona-Sanchez \\ School of Electrical \& Electronic \\ Engineering, University of \\ Manchester, Manchester, UK \\ G. Nenadic \\ School of Computer Science, \\ University of Manchester, \\ Manchester, UK
}

\begin{abstract}
At present, over 1500 offshore wind turbines (OWTS) are operating in the UK with a capacity of 5.4GW. Until now, the research has mainly focused on how to minimise the CAPEX, but Operation and Maintenance (O\&M) can represent up to $39 \%$ of the lifetime costs of an offshore wind farm, mainly due to the assets' high cost and the harsh environment in which they operate. Focusing on O\&M, the HOME Offshore research project (www.homeoffshore.org) aims to derive an advanced interpretation of the faul mechanisms through holistic multiphysics modelling of the wind farm.

With the present work, an advanced model of dynamics for a single wind turbine is developed, able to identify the couplings between aero-hydro-servo-elastic (AHSE) dynamics and drive train dynamics. The wind turbine mechanical components, modelled using an AHSE dynamic model, are coupled with a detailed representation of a variable-speed direct-drive $5 \mathrm{MW}$ permanent magnet synchronous generator (PMSG) and its fully rated voltage source converters (VSCs). Using the developed model for the wind turbine, several case studies are carried out for above and below rated operating conditions. Firstly, the
\end{abstract}

response time histories of wind turbine degrees of freedom (DOFs) are modelled using a full-order coupled analysis. Subsequently, regression analysis is applied in order to correlate DOFs and generated rotor torque (target degree of freedom for the failure mode in analysis), quantifying the level of inherent coupling effects. Finally, the reduced-order multiphysics models for a single offshore wind turbine are derived based on the strength of the correlation coefficients. The accuracy of the proposed reduced-order models is discussed, comparing it against the full-order coupled model in terms of statistical data and spectrum. In terms of statistical results, all the reducedorder models have a good agreement with the full-order results. In terms of spectrum, all the reduced-order models have a good agreement with the full-order results if the frequencies of interest are below $0.75 \mathrm{~Hz}$.

\section{INTRODUCTION}

Renewables cover more than $30 \%$ of the current UK power market, where wind energy is the fastest-growing sector. As a world leader in offshore wind energy, UK has announced to invest nearly $£ 19 \mathrm{bn}$ in the offshore wind industry before 2021[1]. 
Wind farm modelling has been mainly focused on the aerodynamics, however, holistic dynamic model of wind turbines [2] are necessary when employing the models for operation and maintenance (O\&M) purpose. For single wind turbines, advanced aero-hydro-servo-elastic (AHSE) dynamic models have been widely applied in wind turbine design and analysis[3]. However, these studies have mainly focused on the analysis of structural and mechanical parts of turbines. In the AHSE models the electrical part is generally highly simplified, by the use of look-up tables and/or simplified model for the generator. On the other hand, detailed models of the electrical components, including the generator, converter and AC/DC link, etc. have been widely developed in the past few decades.Analogously, in such models, the non-linear dynamics of the wind turbine are substantially simplified down to an analytical function of blade pitch angle, wind speed and wind turbine angular speed[4,5].

This paper aims to apply an advanced coupled model of dynamics for a single wind turbine. The numerical model includes the AHSE, generator and converter dynamics. considering that the wind energy industry is already very aware of best condition monitoring (CM) and O\&M practices for present systems such as Type 1 to Type 3[6], this paper focuses on the analysis of future systems to be used in $5+$ years, i.e. Type 4 (outlined in Fig. 1):

- Type 1: Fixed speed wind turbines

- Type 2: Limited variable-speed wind turbines (variable slip-resistors)

- Type 3: Variable speed wind turbines with partial-scale power converter

- Type 4: Variable speed wind turbines with full-scale power converter without gearbox.

As regards the wind farm model, offshore wind parks usually consist of tens to hundreds of wind turbines. Dynamic model of a single wind turbine mainly relies on dividing the wind turbine into several rigid bodies[3,7]. However, simply having multiple dynamic models, one for each wind turbine, running in parallel may be computationally expensive. For this reason, reduced-order model (ROM) of the holistic dynamic model of the single wind turbine are the major concern of this paper, providing an effective way to solve the above-mentioned problem. Reduced-order methods have been well studied in the area of control, fluid dynamics, structural analysis, etc.[8-10]. A number of ROMs have been developed for wind farms[11,12], but these models have only focused on modelling the drive train (DT) dynamics within the wind farm. Applying a coupled AHSE and DT dynamic model, this paper aims to develop a data-driven ROM which is sufficient to properly model relevant aspects linked to O\&M, but at the same time saving computation cost.

\section{DEFINITION OF THE 5MW HOME-OFFSHORE WIND TURBINE}

The case studies here considered are based on a 5MW offshore wind turbine, on monopile support structure. The structural parts of the wind turbine, including blades, rotor, tower and monopile, are the same as those for the NREL 5MW baseline offshore wind turbine[13]. As for the drivetrain, a direct-drive configuration has been considered, as shown in Figure 1, eliminating the need for a gearbox, which has been considered as a major failure for wind turbines[2,14]. The main shaft is connected to a PMSG with fully rated VSCs. Parameters used for the PMSG were adapted from[15]. Further information can be found in[6].

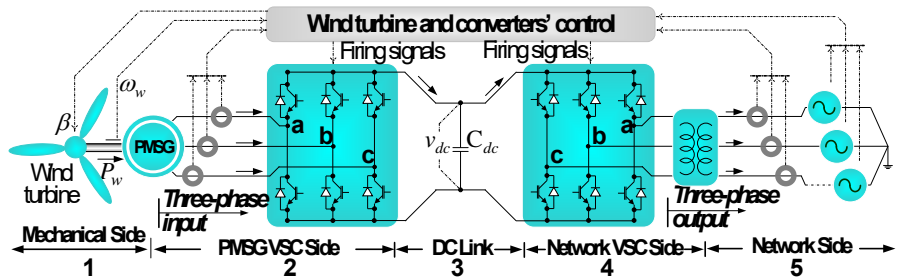

FIGURE 1: VARIABLE-SPEED WIND TURBINE DIRECT-DRIVE-TRAIN PMSG WITH FULL RATED VSCS

\section{METHODOLOGY}

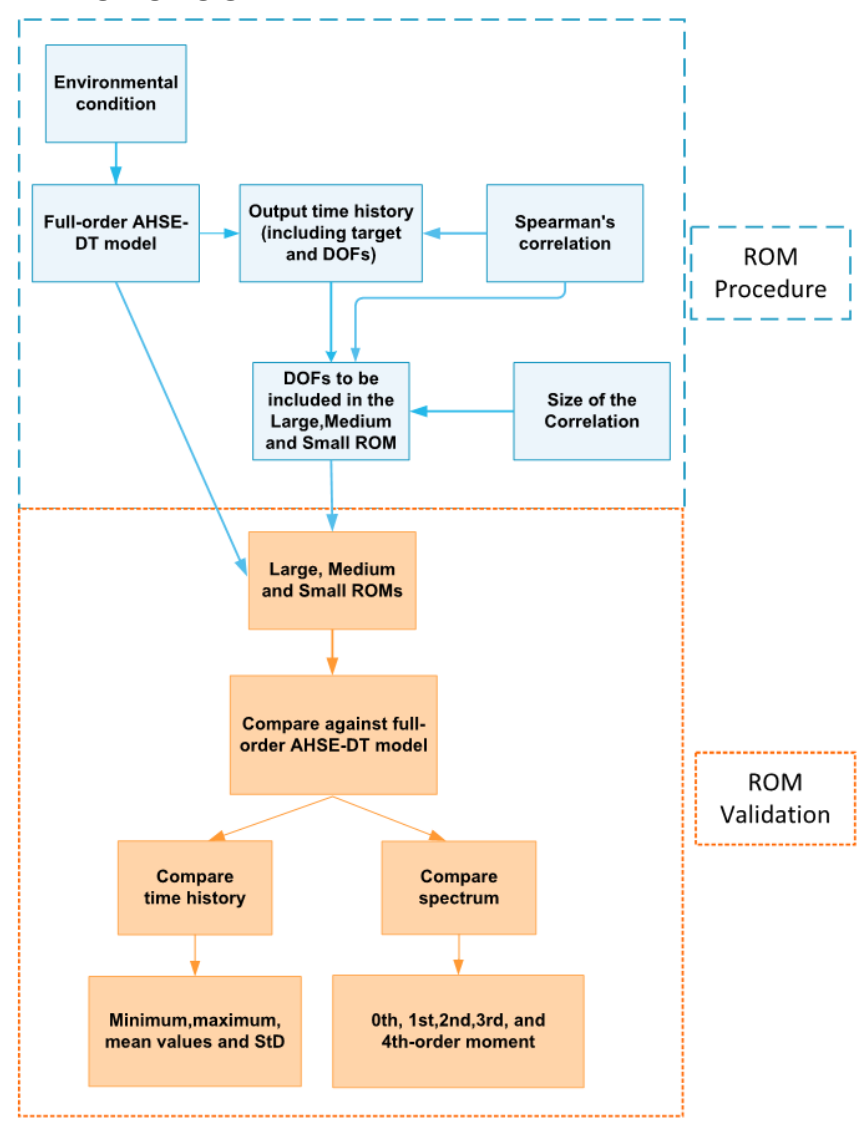

FIGURE 2: BLOCK DIAGRAM OF THE ROM PROCEDURE AND VALIDATIONS OF THE LARGE, MEDIUM AND SMALL ROMS

Figure 2 shows a block diagram of the model order reduction method here applied. Using the AHSE-DT (full-order) model[16], the time history signal of a target output, linked to a chosen failure mechanism, is generated under relevant environmental conditions. A regression analysis is then carried 
out between the target output and all the DOFs considered in the AHSE-DT model, using Spearman's correlation. The final aim is to reduce the computational cost of the complex AHSE-DT coupled model as much as possible.

Applying Cohen's method [17] to quantify the strength of the correlation (Table 1), three reduced-order models (Small, Medium and Large) are proposed. Each reduced-order model is nonlinear (based on the full-order AHSE-DT model), but including a smaller number of DOFs than the full-order one. More specifically, the reduced-order model classified as "large" includes correlation coefficients between -.50 and -1.00 (negative), and between .50 and 1.00 (positive), while the "medium" reduced-order model includes all the correlations with coefficients larger, in absolute value, than 0.30 , i.e. in the range of -.30 to -1.00 (negative) and 0.30 to 1.00 (positive). For the small one, all the correlations stronger than 0.1 (in absolute value), i.e. the correlation coefficients fall in the range of -.10 to -1.00 (negative) and 0.10 to 1.00 (positive). Coefficients in the range of -.09 to .09 are considered as "not correlated".

TABLE 1: SIZE OF THE CORRELATION [17]

\begin{tabular}{|c|c|c|}
\hline & Negative & Positive \\
\hline Small & -.10 to -.29 & .10 to .29 \\
\hline Medium & -.30 to -.49 & .30 to .49 \\
\hline Large & -.50 to -1.00 & .50 to 1.00 \\
\hline
\end{tabular}

\section{Wind turbine system coupled nonlinear (AHSE-DT) model}

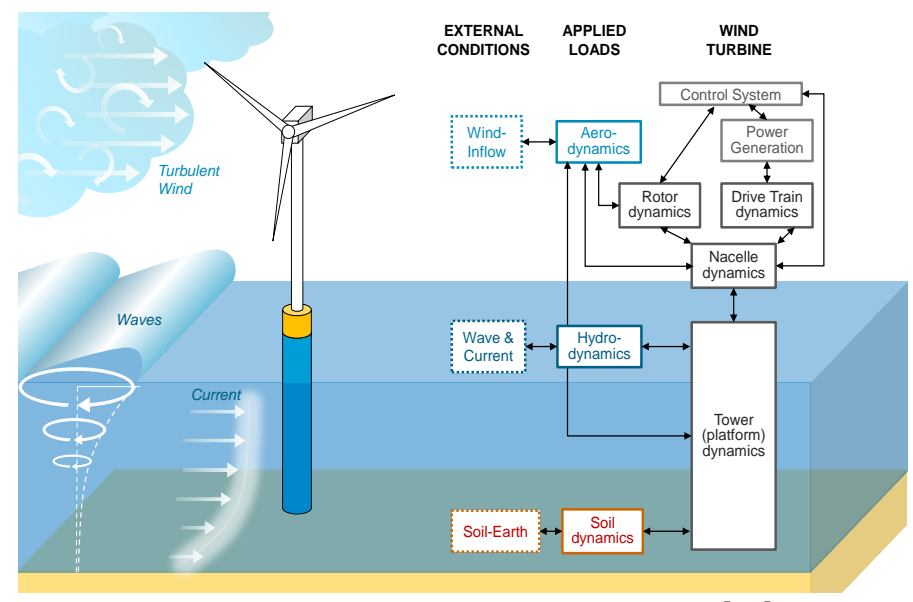

FIGURE 3: AHSE-DT MODEL ADAPTED FROM[18]

Figure 3 shows the main features of the AHSE-DT coupled nonlinear model used in this paper. For the aerodynamic forces, the Blade-Element Momentum (BEM) of the AeroDyn15 module of FAST has been adopted. The influence of the tower on the wind local to the blades is considered using an analytical potential-flow theory, but wind loading on the tower is calculated quasi-statically[16]. As for the electric dynamics, whose topology has already been introduced in Figure 1, the PMSG has been modelled by the well-known $q d$ model $[4,19]$ and operated, together with its VSC, by vector control means. The network link dynamics have been modelled in the $d q$ frame. Note that for the PMSG, the q-axis is chosen as the main axis to model the machine. So the model is usually called $q d$. For the network link dynamics, the d-axis is chosen as the main axis to model such dynamics, hence the model is usually called $d q$. A more detailed description on the numerical model of the PMSG and VSC can be found in[6].

\section{Regression Analysis}

Spearman Rank Correlation [20] is the application of Pearson Correlation to ranked variables and is defined as follows:

$r_{s}=\rho_{r g_{X}, r g_{Y}}=\frac{\operatorname{cov}\left(r g_{X}, r g_{Y}\right)}{\sigma_{r g_{X}} \sigma_{r g_{Y}}}=1-\frac{6 \sum d_{i}{ }^{2}}{n\left(n^{2}-1\right)}$

where $\operatorname{cov}\left(r g_{X}, r g_{Y}\right)$ is the covariance, $\sigma_{r g_{X}}, \sigma_{r g_{Y}}$ are the standard deviations of the rank variables, $n$ denotes the number of observations in $X$ and $Y$, and $d_{i}$ is the difference between the two ranks for each observation.

In contrast to Pearson, Spearman Correlation can be applied when one or both variables are skewed or ordinal and is robust when extreme values are present[21]. Moreover, Spearman correlation measures a broader class of association between variables than Pearson: it can uncover non-linear relationships as long as they are monotonic[22].

\section{RESULTS AND DISCUSSIONS}

\section{Target DOF and Load Cases Definition}

As for the previous study[2], the rotor torque has been selected as a target output and DOF. Its monitoring (actual and/or in simulations) has been shown to have the potential to foreseen some major failure of the gearbox, being closely linked to the dynamics of its main components[23]. In this study, for a direct-drive configuration, this signal and its dependency on the other DOF is analysed, being the main dynamic link to the newly coupled model of the electro-dynamics of the generator and converter model.

Analogously to[2], a wind-only condition has been considered, not being interested in including the hydrodynamic loadings in the study. Two wind conditions are considered:

- Below rated $(6 \mathrm{~m} / \mathrm{s})$ turbulent wind

- Above rated $(18 \mathrm{~m} / \mathrm{s})$ turbulent wind

For the stochastic wind simulation, Kaimal turbulence model and normal turbulence type were applied. The turbulence intensity is based on the IEC type C[24]. The inflow wind time histories are generated by using a stochastic turbulence tool, TurbSim[24]. Each load case has a total length of 10 minutes, and for each load case, due to the nature of aerodynamics, five realisations have been performed to capture the stochastic responses of wind turbine. Figures 4(a) and (b) show time history of the first realisations for the two wind conditions, respectively, where (as for the other output signals) the first $50 \mathrm{~s}$ are not included to eliminate the transient regime. 


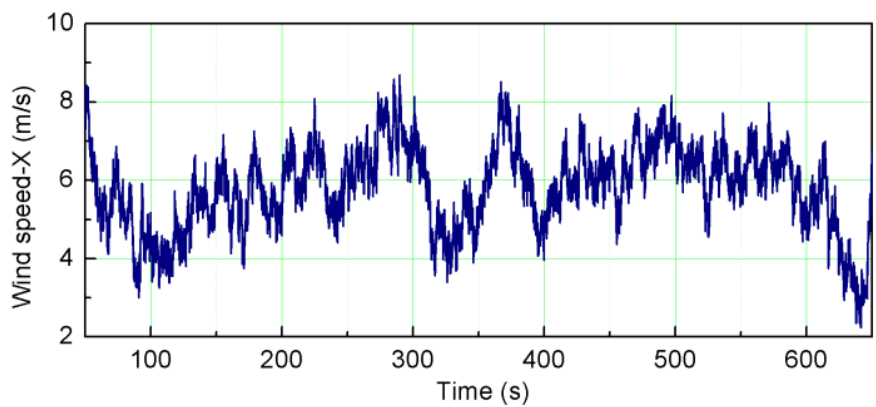

FIGURE 4 (a): HORIZONTAL (X-DIRECTION) WIND SPEED TIME HISTORY $(6 \mathrm{~m} / \mathrm{s})$

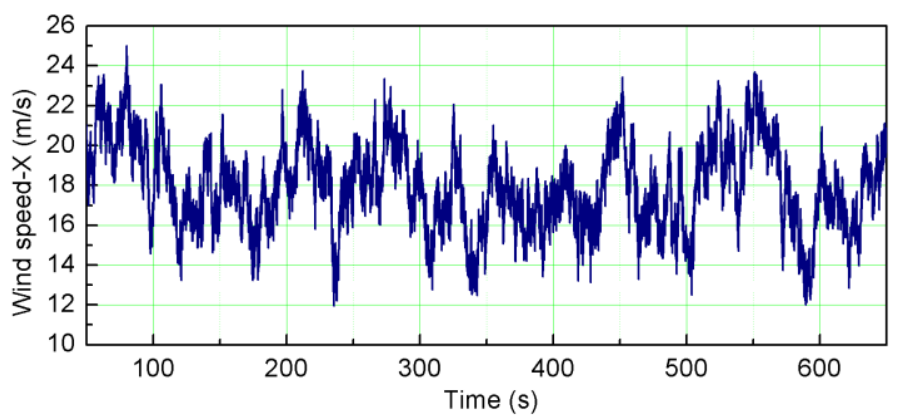

FIGURE 4 (b): HORIZONTAL(X-DIRECTION) WIND SPEED TIME HISTORY $(18 \mathrm{~m} / \mathrm{s})$

\section{Correlation strength}

TABLE 2 (a) CORRELATION COEFFICIENTS BETWEEN ROTOR TORQUE AND DOFs $(6 \mathrm{~m} / \mathrm{s})$

\begin{tabular}{|c|c|c|c|c|c|c|}
\hline \multirow{2}{*}{ DOFs } & \multicolumn{5}{|c|}{ Realisations } & \multirow{2}{*}{$\begin{array}{c}\text { Correlation } \\
\text { strength }\end{array}$} \\
\cline { 2 - 6 } & 1 & 2 & 3 & 4 & 5 & NC \\
\hline Blade1 First edgewise mode & NC & NC & NC & NC & NC & NC \\
\hline Blade2 First edgewise mode & NC & NC & NC & NC & NC & NC \\
\hline Blade3 First edgewise mode & NC & NC & NC & NC & NC & N \\
\hline Blade1 First flapwise mode & L & L & L & L & L & L \\
\hline Blade2 First flapwise mode & L & L & L & L & L & L \\
\hline Blade3 First flapwise mode & L & L & L & L & L & L \\
\hline Blade1 Second flapwise mode & NC & NC & NC & NC & NC & NC \\
\hline Blade2 Second flapwise mode & NC & NC & NC & NC & NC & NC \\
\hline Blade3 Second flapwise mode & NC & NC & NC & NC & NC & NC \\
\hline $\begin{array}{c}\text { Generator Azimuth } \\
\text { Nende- }\end{array}$ & 0 & 0 & 0 & 0 & 0 & $\begin{array}{c}\text { Always } \\
\text { included }\end{array}$ \\
\hline $\begin{array}{c}\text { Nacelle Yaw } \\
\text { bending mode }\end{array}$ & NC & S & NC & NC & S & NC \\
\hline $\begin{array}{c}\text { First side-to-side tower bending } \\
\text { mode }\end{array}$ & NC & NC & S & NC & S & NC \\
\hline First fore-aft tower bending mode & L & L & L & L & L & L \\
\hline
\end{tabular}

Not Correlated

(NC)

\section{Small}

(S)
(M)

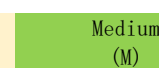

TABLE 2 (b) CORRELATION COEFFICIENTS BETWEEN ROTOR TORQUE AND DOFs $(18 \mathrm{~m} / \mathrm{s})$

\begin{tabular}{|c|c|c|c|c|c|c|}
\hline \multirow{2}{*}{ DOFs } & \multicolumn{5}{|c|}{ Realisations } & \multirow{2}{*}{$\begin{array}{l}\text { Correlation } \\
\text { strength }\end{array}$} \\
\hline & 1 & 2 & 3 & 4 & 5 & \\
\hline Blade1 First edgewise mode & $\mathrm{NC}$ & $\mathrm{NC}$ & NC & $\mathrm{NC}$ & $\mathrm{NC}$ & $\mathrm{NC}$ \\
\hline Blade2 First edgewise mode & $\mathrm{NC}$ & $\mathrm{NC}$ & NC & $\mathrm{NC}$ & $\mathrm{NC}$ & $\mathrm{NC}$ \\
\hline Blade3 First edgewise mode & $\mathrm{NC}$ & $\mathrm{NC}$ & NC & $\mathrm{NC}$ & $\mathrm{NC}$ & $\mathrm{NC}$ \\
\hline Blade1 First flapwise mode & $\mathrm{NC}$ & $\mathrm{NC}$ & NC & $\mathrm{NC}$ & $\mathrm{NC}$ & $\mathrm{NC}$ \\
\hline Blade2 First flapwise mode & $\mathrm{NC}$ & $\mathrm{NC}$ & NC & $\mathrm{NC}$ & $\mathrm{NC}$ & $\mathrm{NC}$ \\
\hline Blade3 First flapwise mode & $\mathrm{NC}$ & $\mathrm{NC}$ & NC & $\mathrm{NC}$ & $\mathrm{NC}$ & $\mathrm{NC}$ \\
\hline Blade1 Second flapwise mode & M & S & $\mathrm{S}$ & S & S & $S$ \\
\hline Blade2 Second flapwise mode & M & S & S & S & S & S \\
\hline Blade3 Second flapwise mode & S & S & S & $\mathrm{S}$ & S & S \\
\hline Generator Azimuth & 0 & 0 & 0 & 0 & 0.01 & $\begin{array}{l}\text { Always } \\
\text { included }\end{array}$ \\
\hline Nacelle Yaw & $\mathrm{S}$ & S & NC & $\mathrm{S}$ & $\mathrm{NC}$ & $S$ \\
\hline First fore-aft tower bending mode & $\mathrm{L}$ & M & M & M & M & M \\
\hline $\begin{array}{l}\text { First side-to-side tower bending } \\
\text { mode }\end{array}$ & M & M & S & $\mathrm{S}$ & S & $S$ \\
\hline $\begin{array}{l}\text { Second fore-aft tower bending } \\
\text { mode }\end{array}$ & $\mathrm{S}$ & $\mathrm{S}$ & $\mathrm{S}$ & $\mathrm{NC}$ & $\mathrm{NC}$ & $\mathrm{S}$ \\
\hline $\begin{array}{l}\text { Second side-to-side tower } \\
\text { bending mode }\end{array}$ & $\mathrm{L}$ & $\mathrm{L}$ & $\mathrm{L}$ & $\mathrm{L}$ & $\mathrm{L}$ & $\mathrm{L}$ \\
\hline $\begin{array}{l}\text { Not Correlated } \\
(\mathrm{NC})\end{array}$ & & & Med & & & $\begin{array}{l}\text { Large } \\
\text { (L) }\end{array}$ \\
\hline
\end{tabular}

The correlation coefficients and correlation strength between rotor torque and the other DOFs are shown in Table 2 ( $a$ and $b$ ), for the wind conditions and under five realizations simulated. The strength of the correlation is defined as the most occurring one across the five realisations. For instance, in the 18 $\mathrm{m} / \mathrm{s}$ wind-only condition, the first fore-aft tower bending mode showed a large correlation coefficient with the rotor torque, while medium correlation strength is observed on the other four realisations. Thus, the final strength between rotor torque and the first fore-aft tower bending mode is medium.

Tower modes are less sensitive on wind speeds. They both have a relatively high size of correlation, compared with other modes. Different from tower modes, the blade first flapwise mode is largely correlated with the rotor torque at $6 \mathrm{~m} / \mathrm{s}$ wind speed, becoming non-correlated when wind speed increased to above-rated $(18 \mathrm{~m} / \mathrm{s})$. First fore-aft and second side-to-side bending modes are both relatively highly correlated with the rotor torque, while the other tower's bending modes show a lower correlation strength with rotor torque.

\section{$6 \mathrm{~m} / \mathrm{s}$ turbulent wind-only condition}

As defined in Table 1, DOFs for different ROMs levels, at $6 \mathrm{~m} / \mathrm{s}$, are shown in Table 3. The full-order model indicates an advanced coupled nonlinear model including all the DOFs, while the other ROMs are nonlinear models with a selected number of DOFs. The DOF of the generator was enabled in all the case studies, being the target one, and to comply with a variable-speed generator. At below-rated wind conditions, a large ROM 
includes the first blade flapwise mode, the first fore-aft tower bending mode, and the second-order tower side-to-side bending mode. For the small ROM, the tower second fore-aft bending mode is additionally included. According to the strength of correlation (Table 1 and Table 2), it is not possible to identify a medium ROM for the $6 \mathrm{~m} / \mathrm{s}$ turbulent wind-only condition.

TABLE 3: DOFS FOR BELOW-RATED WIND ONLY CONDITION, $6 \mathrm{~m} / \mathrm{s}$

\begin{tabular}{|l|c|c|c|}
\hline \multicolumn{1}{|c|}{ DOFs } & Full order & Small & Large \\
\hline First flapwise blade mode & $\checkmark$ & $\checkmark$ & $\checkmark$ \\
\hline $\begin{array}{l}\text { Second flapwise blade } \\
\text { mode }\end{array}$ & $\checkmark$ & & \\
\hline First edgewise blade mode & $\checkmark$ & & \\
\hline Generator & \multicolumn{2}{|c|}{ Always included } \\
\hline Yaw & $\checkmark$ & & $\checkmark$ \\
\hline $\begin{array}{l}\text { First fore-aft tower } \\
\text { bending mode }\end{array}$ & $\checkmark$ & $\checkmark$ & \\
\hline $\begin{array}{l}\text { Second fore-aft tower } \\
\text { bending mode }\end{array}$ & $\checkmark$ & $\checkmark$ & \\
\hline $\begin{array}{l}\text { First side-to-side tower } \\
\text { bending mode }\end{array}$ & $\checkmark$ & & $\checkmark$ \\
\hline $\begin{array}{l}\text { Second side-to-side tower } \\
\text { bending mode }\end{array}$ & $\checkmark$ & $\checkmark$ & \\
\hline
\end{tabular}

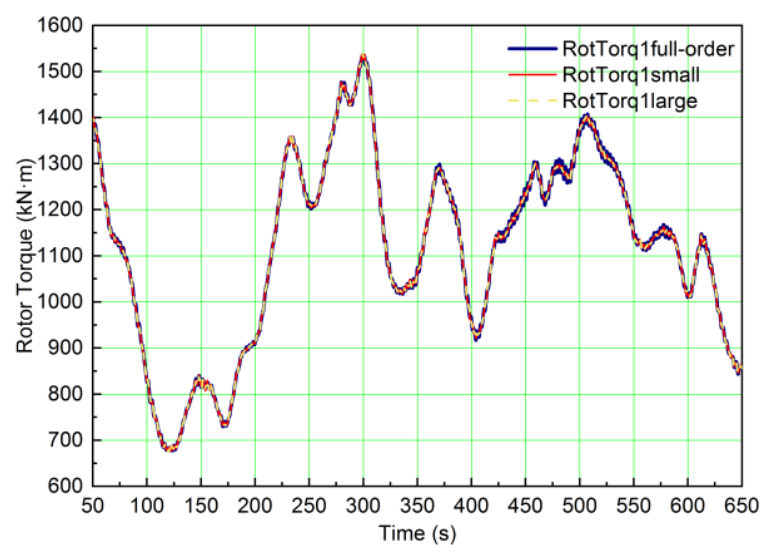

FIGURE 5(a): COMPARISON OF ROTOR TORQUE SIGNAL, 6m/s WIND ONLY CONDITION

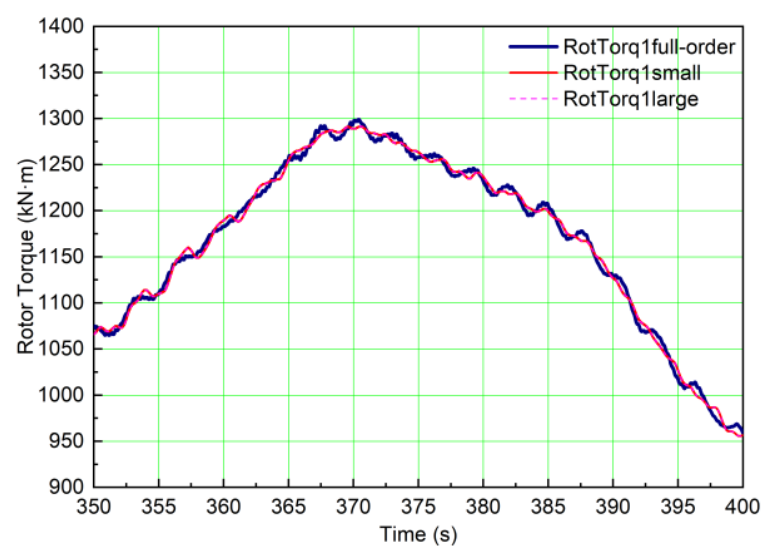

FIGURE 5(b): COMPARISON OF ROTOR TORQUE SIGNAL, 6m/s WIND ONLY CONDITION - CLOSE UP
A comparison of the rotor torque time histories (the first realisation) for the full-order model and the ROMs is shown in Figure 5. As can be seen from Figure 5(b), there are some discrepancies between the full-order model and the ROMs, but the statistical results show a very good agreement (Table 4 and Figure 6).The errors on both mean values and standard deviation (StDs) are less than $1 \%$. The error on the minimum and maximum values have a slight increase, but they remain less than $5 \%$. These discrepancies can be observed in the time histories of Figure 5(b) as well. Neither small nor large ROM captures the higher frequency components of rotor torque while both have a good estimation of the mean rotor torque signals.

TABLE 4: GENERATOR TORQUE SIGNAL, STATISTICS FOR DIFFERENT MODEL REDUCTION (TIME HISTORY, $6 \mathrm{~m} / \mathrm{s}$ )

\begin{tabular}{|l|l|l|l|}
\hline & Full order & Small & Large \\
\hline Mean & 1162.47 & 1162.48 & 1162.48 \\
\hline StD & 252.45 & 252.46 & 252.46 \\
\hline Min & 617.74 & 618.3 & 618.3 \\
\hline Max & 1694 & 1696.6 & 1696.4 \\
\hline
\end{tabular}

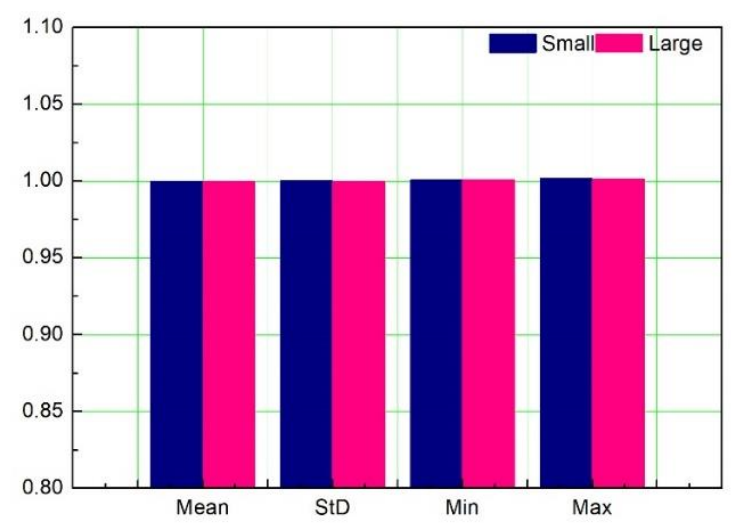

FIGURE 6: GENERATOR TORQUE SIGNAL, STATISTICS FOR DIFFERENT MODEL REDUCTION, NORMALISED AGAINST FULL ORDER VALUES, $(6 \mathrm{~m} / \mathrm{s})$ WIND ONLY CONDITION

For comparisons and discussions between the full-order model and ROMs, a list of system natural frequencies is shown in Table 5. The MSA shown in Figures 7 and 11 denotes the mean squared amplitude. As for the spectrum (Figure 7), both ROMs are able to capture the same low frequency responses (under 0.75 $\mathrm{Hz}$ ) as the full order model. The peak value at $3 \mathrm{~Hz}$, equivalent to the tower's second-order bending modes (Figure 7 and Table 5 ), can be captured by the full-order model only, although the $2^{\text {nd }}$-order tower bending mode was included in the small ROM as well. Unlike the statistical data, only zeroth and first moments (mean values) of the spectrum have a difference of less than $95 \%$, compared with the full order model. Kurtosis $\left(4^{\text {th }}\right.$-order moment) of the ROMs is nearly double the full-order model (Table 6 and Figure 8).

Based on the current results considering the statistical data and spectra, the large ROM tends to be the best alternative to the 
full-order simulations, but only for low frequencies. It shows the same accuracy as the small one, while including fewer DOFs.

\begin{tabular}{|l|l|}
\hline \multicolumn{2}{|c|}{ TABLE 5 NATURAL FREQUENCIES [13] } \\
\hline Mode & FAST (Hz) \\
\hline 1st Blade Asymmetric Flapwise Yaw & 0.6664 \\
\hline 1 st Blade Asymmetric Flapwise Pitch & 0.6675 \\
\hline 1st Blade Collective Flap & 0.6993 \\
\hline 1st Blade Asymmetric Edgewise Pitch & 1.0793 \\
\hline 1st Blade Asymmetric Edgewise Yaw & 1.0898 \\
\hline 2nd Blade Asymmetric Flapwise Yaw & 1.9337 \\
\hline 2nd Blade Asymmetric Flapwise Pitch & 1.9223 \\
\hline 1st Tower Fore-Aft & 0.3240 \\
\hline 1st Tower Side-to-Side & 0.3120 \\
\hline 2nd Tower Fore-Aft & 2.9003 \\
\hline 2nd Tower Side-to-Side & 2.9361 \\
\hline 1st Drivetrain Torsion & 0.6205 \\
\hline
\end{tabular}

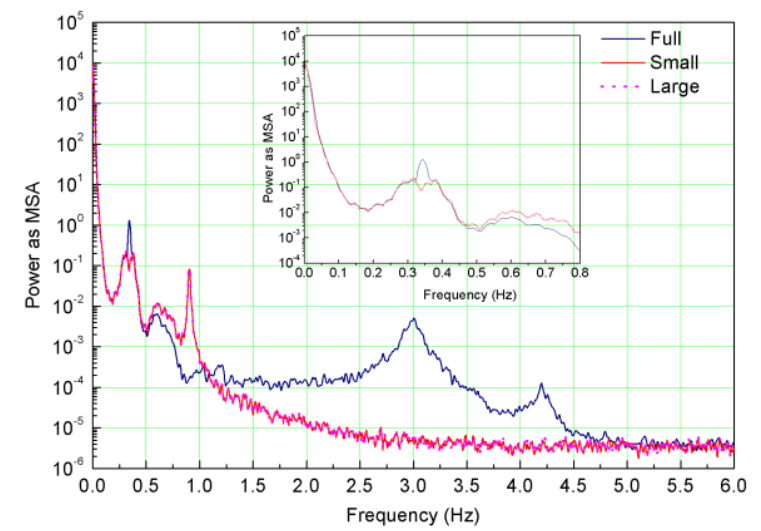

FIGURE 7: COMPARISON OF ROTOR TORQUE SPECTRUM, $6 \mathrm{~m} / \mathrm{s}$ WIND ONLY CONDITION

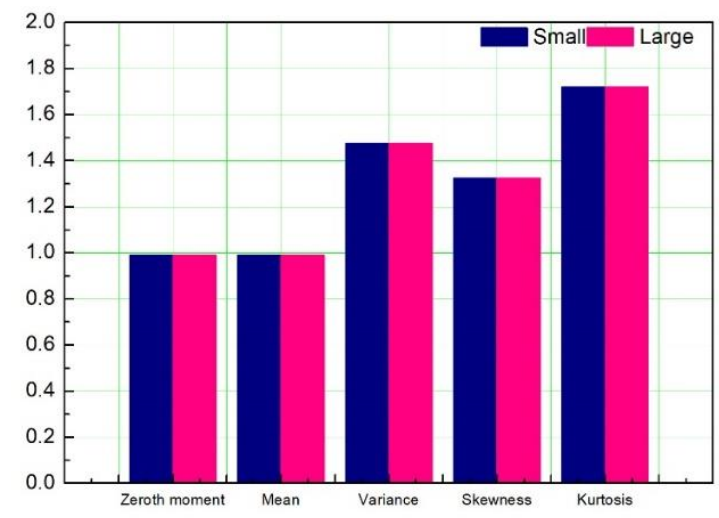

FIGURE 8: GENERATOR TORQUE SPECTRUM, STATISTICS FOR DIFFERENT MODEL REDUCTION, NORMALISED AGAINST FULL ORDER VALUES, $(6 \mathrm{~m} / \mathrm{s})$ WIND ONLY CONDITION
TABLE 6: GENERATOR TORQUE SPECTRUM, STATISTICS FOR DIFFERENT MODEL REDUCTION (SPECTRUM, $6 \mathrm{~m} / \mathrm{s}$ )

\begin{tabular}{|l|l|l|l|}
\hline & Full order & Small & Large \\
\hline Zeroth & 83.67 & 82.84 & 82.84 \\
\hline Mean & 14.40 & 14.26 & 14.26 \\
\hline Variance & 83309.21 & 122870.81 & 122869.83 \\
\hline Skewness & 25.00 & 33.15 & 33.15 \\
\hline Kurtosis & 696.03 & 1197.50 & 1197.53 \\
\hline
\end{tabular}

\section{$18 \mathrm{~m} / \mathrm{s}$ turbulent wind-only condition}

TABLE 7: DOFS FOR ABOVE-RATED WIND ONLY CONDITION, 18m/s
\begin{tabular}{|l|c|c|c|c|}
\hline DOFs & $\begin{array}{l}\text { Full } \\
\text { order }\end{array}$ & Small & Medium & Large \\
\hline First flapwise blade mode & $\checkmark$ & & & \\
\hline $\begin{array}{l}\text { Second flapwise blade } \\
\text { mode }\end{array}$ & $\checkmark$ & $\checkmark$ & & \\
\hline $\begin{array}{l}\text { First edgewise blade } \\
\text { mode }\end{array}$ & $\checkmark$ & & & \\
\hline Generator & $\checkmark$ & $\checkmark$ & & \\
\hline Yaw & $\checkmark$ & $\checkmark$ & $\checkmark$ & \\
\hline $\begin{array}{l}\text { First fore-aft tower } \\
\text { bending mode }\end{array}$ & $\checkmark$ & $\checkmark$ & & \\
\hline $\begin{array}{l}\text { Second fore-aft tower } \\
\text { bending mode }\end{array}$ & $\checkmark$ & $\checkmark$ & & \\
\hline $\begin{array}{l}\text { First side-to-side tower } \\
\text { bending mode }\end{array}$ & $\checkmark$ & $\checkmark$ & $\checkmark$ & \\
\hline $\begin{array}{l}\text { Second side-to-side tower } \\
\text { bending mode }\end{array}$ & $\checkmark$ & & \\
\hline
\end{tabular}

When it comes to over-rated wind speeds, modes regarding tower bending modes follow almost the same trend between below rated and above rated wind speeds, while blades second flapwise modes have seen an opposite trend (Table 2). It is interesting to notice that for the load case at $18 \mathrm{~m} / \mathrm{s}$, only the second side-to-side tower bending-mode, is included in the large ROM. The medium ROM includes one more mode (tower first fore-aft bending mode), but no significant difference can be noticed in the time signals of the large and the medium ROMs (Figure 9). Large ROM shows a difference of less than $1 \%$ in terms of mean value, compared to the full-order model. Higher discrepancy is in the StD of the large ROM, but the differences are less than $5 \%$. Discrepancies on maximum and minimum values are both within $95 \%$. This is the same for all the ROMs, although the small ROM includes a significantly higher number of DOFs compared with the other ROMs (Figure 9 and Table 7).

Similar to the $6 \mathrm{~m} / \mathrm{s}$ condition, good agreements have been shown at frequencies lower than $0.75 \mathrm{~Hz}$ (Figure 11). None of the ROMs is capable of capturing a peak value at $3 \mathrm{~Hz}$. Nonetheless, the small ROM shows a better agreement with the full-order results, compared to the medium and the large reduced model. Statistical values of the spectrum are in agreement with the time history: they all have shown a less than $5 \%$ differences. Kurtosis ( $3^{\text {rd }}$-order moment) and skewness ( $4^{\text {th }}$-order moment) see a very good agreement between ROMs and the full-order model, although the large ROM has a relatively larger 
discrepancy compared with the small and medium ROMs (Table 9 and Figure 12). Based on these results, the large ROM is recommended for frequencies lower than $0.75 \mathrm{~Hz}$. It captures the same statistical data and spectrum variables as the small and medium ROMs but includes a smaller number of DOFs. The small ROM is suggested for frequency higher than $0.75 \mathrm{~Hz}$. It captures better higher frequency components of the full-order model.

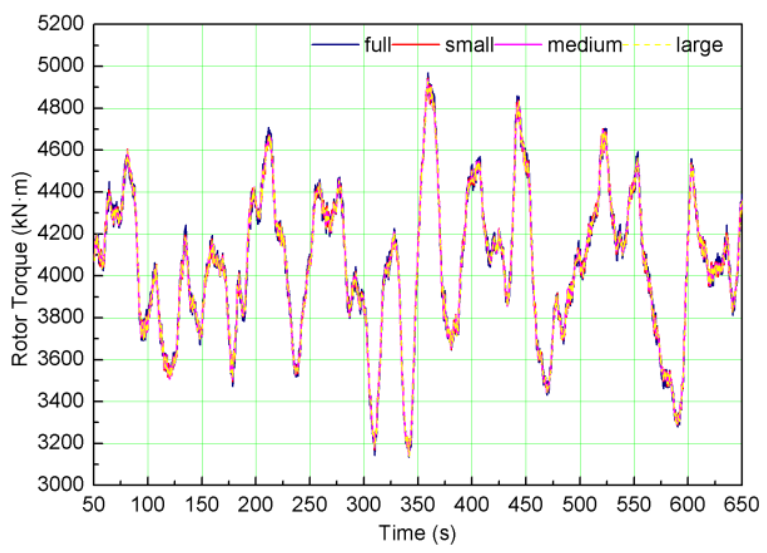

FIGURE 9(a): COMPARISON OF ROTOR TORQUE SIGNAL, 18m/s WIND ONLY CONDITION

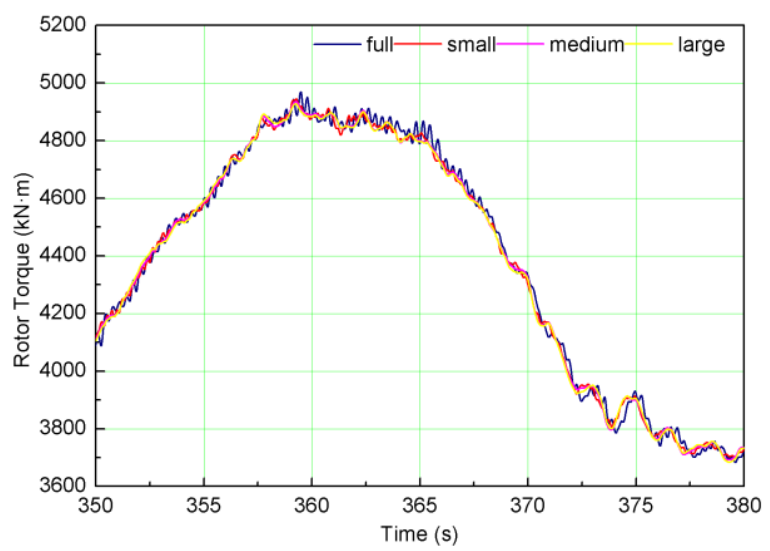

FIGURE 9(b): COMPARISON OF ROTOR TORQUE SIGNAL, 18m/s WIND ONLY CONDITION- CLOSE UP

TABLE 8: GENERATOR TORQUE SIGNAL, STATISTICS FOR DIFFERENT MODEL REDUCTION (TIME HISTORY, 18m/s)

\begin{tabular}{|l|l|l|l|l|}
\hline & Full order & Small & Medium & Large \\
\hline Mean & 4044.86 & 4044.73 & 4044.73 & 4044.70 \\
\hline StD & 316.18 & 312.46 & 312.49 & 311.97 \\
\hline Min & 3257.8 & 3271.6 & 3271.4 & 3270.4 \\
\hline Max & 4945.6 & 4912.2 & 4912 & 4909 \\
\hline
\end{tabular}

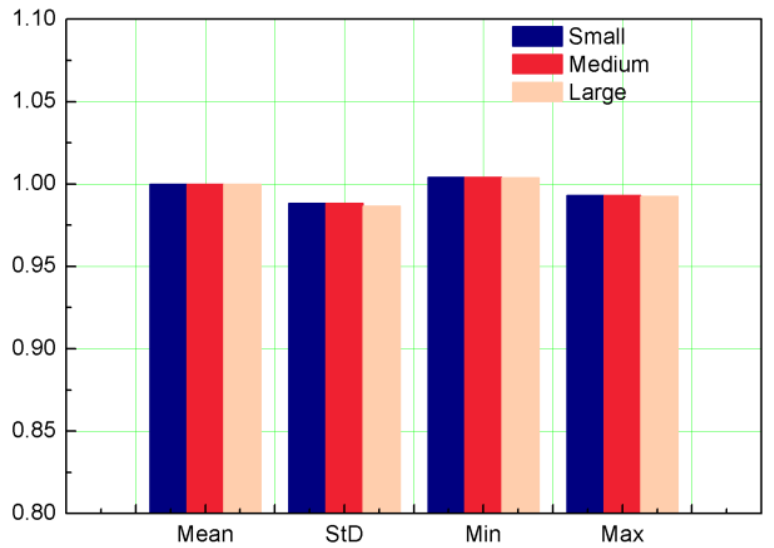

FIGURE 10: GENERATOR TORQUE SIGNAL, STATISTICS FOR DIFFERENT MODEL REDUCTION, NORMALISED AGAINST FULL ORDER VALUES, $(18 \mathrm{~m} / \mathrm{s})$ WIND ONLY CONDITION

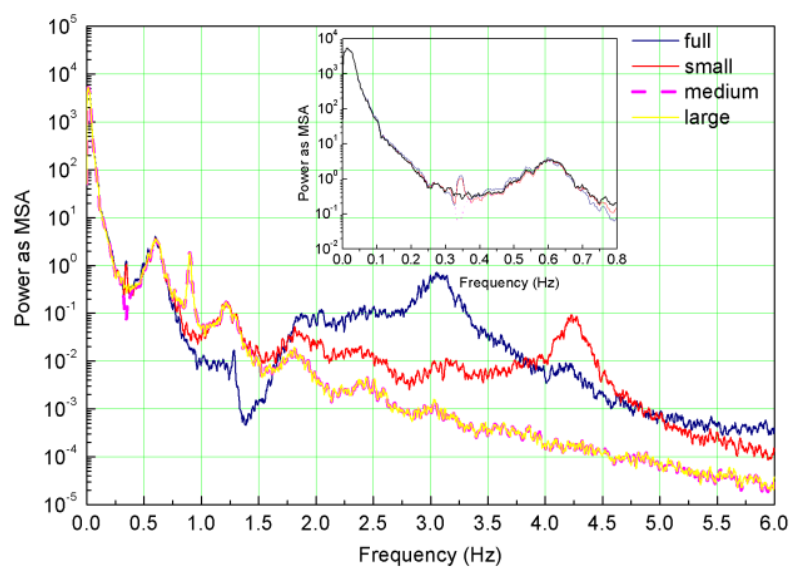

FIGURE 11: COMPARISON OF ROTOR TORQUE SPECTRUM, $18 \mathrm{~m} / \mathrm{s}$ WIND ONLY CONDITION

TABLE 9: GENERATOR TORQUE SPECTRUM, STATISTICS FOR DIFFERENT MODEL REDUCTION (TIME HISTORY, 18m/s)

\begin{tabular}{|l|l|l|l|l|}
\hline & Full order & Small & Medium & Large \\
\hline Zeroth & 178.77 & 173.83 & 173.89 & 173.36 \\
\hline Mean & 29.78 & 28.96 & 28.97 & 28.88 \\
\hline Variance & 139638.99 & 133476.32 & 133573.79 & 133002.53 \\
\hline Skewness & 16.58 & 16.66 & 16.66 & 16.68 \\
\hline Kurtosis & 322.03 & 326.28 & 326.24 & 327.06 \\
\hline
\end{tabular}




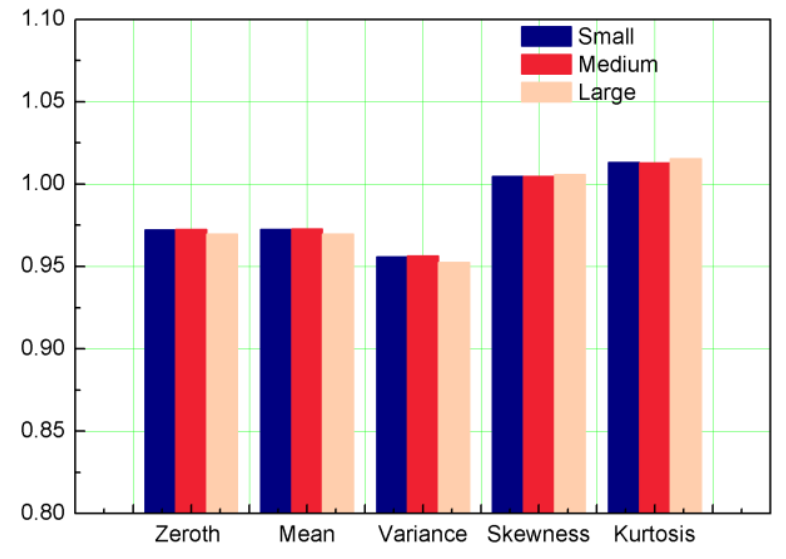

FIGURE 12: GENERATOR TORQUE SPECTRUM, STATISTICS FOR DIFFERENT MODEL REDUCTION, NORMALISED AGAINST FULL ORDER VALUES, $(18 \mathrm{~m} / \mathrm{s})$ WIND ONLY CONDITION

\section{CONCLUSIONS}

This paper has investigated a data-driven reduced-order method for a single wind turbine. A 5MW offshore wind turbine on a monopile, with a direct-drive-train and PMSG, was introduced. Three nonlinear ROMs have been proposed and their accuracies have been discussed against the full-order model, in terms of statistical data and spectra. A summary of the three ROMs at $6 \mathrm{~m} / \mathrm{s}$ and $18 \mathrm{~m} / \mathrm{s}$ is shown in Table 10 . The accuracy of the proposed ROMs is shown as follows:

TABLE 10 (a): SUMMARY OF ROMS AT 6m/s AND 18m/s WIND ONLY CONDITION (TIME HISTORY)

\begin{tabular}{|c|c|c|c|c|c|}
\hline \multirow{2}{*}{$\begin{array}{c}\text { Wind } \\
\text { speed } \\
{[\mathrm{m} / \mathrm{s}]}\end{array}$} & \multirow{2}{*}{$\begin{array}{c}\text { ROM } \\
\text { level }\end{array}$} & \multicolumn{4}{|c|}{ Are they estimated within $95 \%$} \\
\cline { 3 - 6 } & & mean & $\min$ & $\max$ & Std \\
\hline \multirow{2}{*}{6} & Small & YES & YES & YES & YES \\
\cline { 2 - 6 } & Large & YES & YES & YES & YES \\
\hline \multirow{3}{*}{18} & Small & YES & YES & YES & YES \\
\cline { 2 - 6 } & Medium & YES & YES & YES & YES \\
\cline { 2 - 6 } & Large & YES & YES & YES & YES \\
\hline
\end{tabular}

TABLE 10 (b): SUMMARY OF ROMS AT 6m/s AND 18m/s WIND ONLY CONDITION (SPECTRUM)

\begin{tabular}{|c|c|c|c|c|c|c|}
\hline \multirow{2}{*}{$\begin{array}{c}\text { Wind } \\
\text { speed } \\
{[\mathrm{m} / \mathrm{s}]}\end{array}$} & \multirow{2}{*}{$\begin{array}{c}\text { ROM } \\
\text { level }\end{array}$} & \multicolumn{5}{|c|}{ Are they estimated within 95\% } \\
\cline { 3 - 7 } & $0^{\text {th }}$ & $1^{\text {st }}$ & $2^{\text {nd }}$ & $3^{\text {rd }}$ & $4^{\text {th }}$ \\
\hline \multirow{2}{*}{6} & Small & YES & YES & NO & NO & NO \\
\cline { 2 - 7 } & Large & YES & YES & NO & NO & NO \\
\hline \multirow{3}{*}{18} & Small & YES & YES & YES & YES & YES \\
\cline { 2 - 7 } & Medium & YES & YES & YES & YES & YES \\
\cline { 2 - 7 } & Large & YES & YES & YES & YES & YES \\
\hline
\end{tabular}

- For failure mode related to extreme loads (extreme $\max / \mathrm{min}$ of the time signal), the large ROM is recommended for both wind conditions. It is capable to capture as accurately as the full-order model of these extremes, while significantly decrease the number of DOFs, leading to a lower computational cost.
- $\quad$ For failure mode related to fatigue loads, therefore more linked to the frequencies of oscillation, the large ROM is recommended if the frequencies of interest are below $0.75 \mathrm{~Hz}$. For frequencies higher than $0.75 \mathrm{~Hz}$, full-order model should be applied at $6 \mathrm{~m} / \mathrm{s}$ wind only condition. At $18 \mathrm{~m} / \mathrm{s}$ wind only-condition, the small ROM is recommended as it captures better high-frequency components compared with the large and medium ROMs.

- This paper has considered a wind-only condition, at below and above rated wind speeds. A study on a combination of wind, wave and current loading effects will be included in future works.

\section{ACKNOWLEDGMENTS}

The work presented is supported by the UK Engineering and Physical Sciences Research Council (EPSRC) HOME-Offshore project (EPSRC Reference: EP/P009743/1). The fourth author is also supported by grant EP/L016303/1 for Cranfield University and the University of Oxford, Centre for Doctoral Training in Renewable Energy Marine Structures - REMS (http://www.rems-cdt.ac.uk/) from the UK Engineering and Physical Sciences Research Council (EPSRC).

\section{REFERENCES}

[1] "https://www.renewableuk.com/."

[2] Z. Lin, D. Cevasco, and M. Collu, "Progress on the Development of a Holistic Coupled Model of Dynamics for Offshore Wind Farms: Phase I - Aero-Hydro-Servo-Elastic Model, With Drive Train Model, for a Single Wind Turbine," in Proceedings of the ASME 37th International Conference on Ocean, Offshore and Arctic Engineering, 2018, pp. 1-9.

[3] J. M. Jonkman, "Dynamics Modeling and Loads Analysis of an Offshore Floating Wind Turbine," 2007.

[4] H. Ye, B. Yue, X. Li, and K. Strunz, "Modeling and simulation of multi-scale transients for PMSG-based wind power systems," no. March, pp. 1349-1364, 2017.

[5] Y. Xia, K. H. Ahmed, S. Member, and B. W. Williams, "Wind Turbine Power Coefficient Analysis of a New Maximum Power Point Tracking Technique," IEEE Trans. Ind. Electron., vol. 60, no. 3, pp. 1122-1132, 2013.

[6] J. Carmona S, Z. Lin, M. Collu, M. Barnes, O. Marjanovic, and D. Cevasco, "An analysis of the impact of an advanced aero-hydro-servo-elastic model of dynamics on the generator-converter dynamics, for an offshore fixed 5MW PMSG wind turbine," in IET, ACDC conference, 2019.

[7] Y. Li, A. M. Castro, T. Sinokrot, W. Prescott, and P. M. Carrica, "Coupled multi-body dynamics and CFD for wind turbine simulation including explicit wind turbulence," Renew. Energy, vol. 76, pp. 338-361, 2015.

[8] Y. Lee, B. Seo, and E.-T. Lee, "Application of model reduction techniques to jacket structures," Int. J. Steel Struct., vol. 15, no. 1, pp. 1-6, 2015.

[9] H. A. Pulgar-Painemal and M. Negrete-Pincetic, "Wind 
turbine reduced-order model for power system analysis," 2011 10th Int. Conf. Environ. Electr. Eng., no. June 2011, pp. 1-4, 2011.

[10]M. M. Rezaei, M. Behzad, H. Haddadpour, and H. Moradi, "Development of a reduced order model for nonlinear analysis of the wind turbine blade dynamics," Renew. Energy, vol. 76, pp. 264-282, 2015.

[11]S. Ghosh and N. Senroy, "Balanced truncation based reduced order modeling of wind farm," Int. J. Electr. Power Energy Syst., vol. 53, no. 0, pp. 649-655, 2013.

[12]Y. Ni, C. Li, Z. Du, and G. Zhang, "Model order reduction based dynamic equivalence of a wind farm," Int. J. Electr. Power Energy Syst., vol. 83, pp. 96-103, 2016.

[13]J. Jonkman, S. Butterfield, W. Musial, and G. Scott, "Definition of a 5-MW Reference Wind Turbine for Offshore System Development," no. February, 2009.

[14]David S. Ochs, "Design of detailed models for use in fast aeroelastic simulations of permanent-magnet direct-drive wind turbines," Kansas State University, 2010.

[15]Z. C. and M. C. J. Zhang, "Design and comparison of a novel stator interior permanent magnet generator for direct-drive wind turbines," IET Renew. Power Gener, vol. 1, no. 4, pp. 203-210, 2007.

[16]"NWTC Information Portal (FAST v8). https://nwtc.nrel.gov/FAST8. Last modified 27-July-2016; Accessed 19-December-2017." .

[17]J. Cohen, Statistical Power Analysis for the Behavioral Sciences, Second. Edi. Lawrence Erlbaum Associates.

[18]J. Jonkman, "The New Modularization Framework for the FAST Wind Turbine CAE Tool," 51st AIAA Aerosp. Sci. Meet. Grapvine Texas, no. January, 2013.

[19]S. P. Paul Krause, Oleg Wasynczuk, Scott Sudhoff, Analysis of electric machinery and drive systems, Third. IEEE Press, Wiley, 2013.

[20]C.Spearman, "The proof and measurement of association between two things," Am. J. Psychol., vol. 100, no. Special Centennial Issue, pp. 441-471, 1987.

[21]M. MM, "Statistics Corner: A guide to appropriate use of Correlation coefficient in medical research," Malawi Med. J., vol. 24, no. 3, pp. 69-71, 2012.

[22]M. T. Puth, M. Neuhäuser, and G. D. Ruxton, "Effective use of Spearman's and Kendall's correlation coefficients forassociation between two measured traits," Anim. Behav., vol. 102, pp. 77-84, 2015.

[23]A. R. Nejad, Z. Gao, and T. Moan, "Long-term analysis of gear loads in fixed offshore wind turbines considering ultimate operational loadings," Energy Procedia, vol. 35, no. 1876, pp. 187-197, 2013.

[24]"NWTC Information Portal (TurbSim). https://nwtc.nrel.gov/TurbSim. Last modified 14-June2016; Accessed 18-December-2018.”. 